\title{
Malnutrition prevalence in The Netherlands: results of the Annual Dutch National Prevalence Measurement of Care Problems
}

\author{
Judith M. M. Meijers ${ }^{1 *}$, Jos M. G. A. Schols ${ }^{2,3}$, Marian A. E. van Bokhorst-de van der Schueren ${ }^{4}$, \\ Theo Dassen ${ }^{5}$, Maaike A. P. Janssen ${ }^{6}$ and Ruud J. G. Halfens ${ }^{1}$ \\ ${ }^{1}$ Department of Health Care and Nursing Science, Faculty of Health, Medicine and Life Sciences, Maastricht University, \\ PO Box 616, 6200 MD Maastricht, The Netherlands \\ ${ }^{2}$ Department of General Practice, Faculty of Health, Medicine and Life Sciences, Maastricht University, Maastricht, \\ The Netherlands \\ ${ }^{3}$ Scientific Centre for Transformation in Care and Welfare (Tranzo), Tilburg University, Tilburg, The Netherlands \\ ${ }^{4}$ Department of Nutrition and Dietetics, VU University Medical Centre, Amsterdam, The Netherlands \\ ${ }^{5}$ Nursing Science, Charité - Universitätsmedizin, Berlin, Germany \\ ${ }^{6}$ Department of Critical Care, Faculty of Health and Social Studies/Faculty of Nursing, HAN University, Nijmegen, \\ The Netherlands \\ (Received 19 October 2007 - Revised 18 March 2008 - Accepted 8 April 2008 - First published online 5 June 2008)
}

The objective of this study was to provide data on malnutrition prevalence in hospitals, nursing homes and home-care organisations in The Netherlands in a nationally representative sample, and to assess the factors such as age, sex, time since admission, ward type and disease for identifying patients at high risk of malnutrition. A cross-sectional, multi-centre design with a standardised questionnaire was used to measure the prevalence of malnutrition. Nutritional status was assessed by BMI, undesired weight loss and nutritional intake. In this study, 12883 patients were included. The prevalence of malnutrition was the highest in hospitals (23.8\%), followed by home-care organisations (21.7\%) and nursing homes (19.2\%). Logistic regression analysis revealed no association with age, time since admission and ward type. Being female was associated with malnutrition only in nursing homes. Blood diseases, gastrointestinal tract diseases, infection, chronic obstructive pulmonary disease, dementia and cancer were the factors associated with malnutrition in hospitals. Dementia was associated with malnutrition in nursing homes, while gastrointestinal tract diseases, diabetes mellitus and cancer were the associated factors in home care. This study shows that malnutrition is still a substantial problem in hospitals, nursing homes and home care in The Netherlands. Malnutrition is a problem for more than one in five patients. Despite growing attention to the problem, more continued alertness is required.

Malnutrition: Prevalence: Factors: Hospital: Nursing home: Home care

Malnutrition continues to be an important and under-recognised problem in all health-care settings. Malnutrition can encompass both over- and undernutrition as well as deficiencies or imbalances of specific nutrients ${ }^{(1)}$. In this study, malnutrition is described as a state of undernutrition.

The first national survey of malnutrition conducted in 2001 by the dietitians in The Netherlands included 7606 patients, and indicated that approximately $12 \%$ appeared to be malnourished and $13 \%$ at risk of malnutrition in hospitals, nursing homes and home-care organisations ${ }^{(2)}$. Since then, no other large-scale studies of malnutrition prevalence have been performed in The Netherlands.

Comparisons of malnutrition prevalence in patients hospitalised in different European countries reveal that this fluctuates from 20 to $60 \%{ }^{(3)}$. European studies specifically related to the elderly report prevalence ranging from $22 \%$ in Germany up to $84 \%$ in Ireland ${ }^{(4,5)}$. Stratton et al. ${ }^{(6)}$ showed that disease-related malnutrition occurs in hospitals (10-60\%), nursing homes (50\% or more) and among individuals living independently $(>10 \%)$. These prevalence rates for malnutrition fluctuate extensively, as they depend on how malnutrition is operationalised ${ }^{(7-9)}$. As no worldwide consensus on the elements of malnutrition operationalisation has yet been reached, it is very difficult to find a uniform operationalisation covering different patient groups, diseases and settings. It is thus difficult to compare the prevalence rates of malnutrition across different studies, settings, patient groups and countries ${ }^{(6)}$.

Despite these operationalisation differences, the research shows that malnourished individuals consult their general practitioners and are admitted to hospitals or nursing homes more often, and have higher post-operative morbidity and mortality, slower wound-healing processes, longer hospital stays and poorer quality of life $\mathrm{e}^{(10-14)}$. 
Obtaining insight into factors for malnutrition should make it possible to identify subgroups of patients at risk. This may have a positive effect on preventing malnutrition and its consequences ${ }^{(6)}$. The main risk factor, especially in hospitals, home care and nursing homes, is disease ${ }^{(15)}$. There are numerous reasons for this; Stratton et al. ${ }^{(6)}$, for example, highlighted a diversity of disease-related aspects that decrease food intake even when food is available, including loss of appetite, anorexia, nausea, psychological problems and difficulties in chewing, tasting, swallowing and digestion. Furthermore, they demonstrated that nutrient requirements are increased by disease, which indicates that even normal intake could be insufficient for such patients.

Another factor influencing malnutrition is age. Higher age is associated with increased risk of malnutrition, as disease prevalence in this group increases and body composition changes ${ }^{(4,16-20)}$.

Sex, too, is another possible factor that could influence malnutrition as body composition changes occur differently in men and women in the various ageing phases, thus influencing the assessment and screening of malnutrition ${ }^{(21)}$. Perissinotto et al. ${ }^{(19)}$ found an adjusted malnutrition prevalence rate that was higher for women than for men in the elderly. Pirlich et al. ${ }^{(20)}$, however, found no such sex influence.

Due to increasing awareness in developed countries of the importance of recognising malnutrition in health care and the fact that only one extensive study on malnutrition prevalence has been performed in The Netherlands, this study aimed to investigate malnutrition prevalence in Dutch hospitals, nursing homes and home-care organisations on a large representative scale, and to draw more attention from healthcare professionals to the problem of malnutrition. Additionally, the association of factors such as age, sex, disease, ward type and time since admission was assessed to identify patients at risk of malnutrition.

\section{Methods}

\section{Design}

This study is part of the Annual National Prevalence Measurement of Care Problems of Maastricht University (Landelijke Prevalentiemeting Zorgproblemen (LPZ)), which started measuring malnutrition in 2004. The design involves a cross-sectional, multi-centre point prevalence measurement.

\section{Instrument}

A standardised questionnaire was used to register data on the organisation itself, wards included and individual patients, including demographic data, reason for admission (registered in the medical records) and nutritional items such as amount of undesirable weight loss $(6 \mathrm{~kg}$ in the previous 6 months or $3 \mathrm{~kg}$ in the previous month) and nutritional intake (none for $3 \mathrm{~d}$ or reduced for more than $10 \mathrm{~d}$ ). These items were obtained by having trained professionals measure the patients' height and weight. When being weighed, the patients wore light indoor clothes and no shoes, and sat or stood on a calibrated scale. BMI was calculated later by the research group. The nutritional item 'undesired weight loss' was measured in kilograms, as this is faster and simpler for the nurses than calculating the weight-loss percentage. Weight loss was assessed from earlier recorded weights in the charts, or, if missing, from recalled weight.

The large LPZ population is heterogeneous and incorporates patients from different age groups (range: 18-104 years) and settings, further complicating the operationalisation of malnutrition. Based on the literature and consultation with Dutch experts in the field, malnutrition was defined according to one of the three following criteria: (1) BMI less than $18.5 \mathrm{~kg} / \mathrm{m}^{2}$; (2) unintentional weight loss $(6 \mathrm{~kg}$ in the previous 6 months or $3 \mathrm{~kg}$ in the previous month) or (3) BMI between 18.5 and $20 \mathrm{~kg} / \mathrm{m}^{2}$ in combination with no nutritional intake for $3 \mathrm{~d}$ or reduced intake for more than $10 \mathrm{~d}^{(6,9,21-24)}$.

\section{Sample}

For the LPZ study, all health-care organisations in The Netherlands were invited by mail to participate voluntarily. Fifty-seven university and general hospitals $(60.6 \%$ of the Dutch total of 94$)$, thirty-nine nursing homes $(11.3 \%$ of the Dutch total of 345) and nineteen home-care organisations (12.6\% of the Dutch total of 150) were included. Only patients of age 18 years and above were included, as the criteria for defining malnutrition in patients younger than 18 years are complex ${ }^{(9)}$ and vary from the adult population. The LPZ received ethical approval from the University Hospital Maastricht's (azM) Medical Ethical Committee. Likewise, participating organisations were required to obtain approval from their own ethical committees. All patients or their relatives gave informed consent.

\section{Data collection}

The annual LPZ study took place on 4 April 2005. In each participating organisation, one coordinator was responsible for the measurement. The coordinators were trained collectively by the research group on how to manage the survey within the organisation, and how to use the printed standardised questionnaire and specially designed Internet data-entry program. The coordinators also received a protocol and training package to support them in training the health-care professionals who would perform the measurement within the organisations.

To achieve an objective judgment for every patient, two health-care professionals (nurses, dietitians or doctors, one of whom worked in the patient's ward and the other independent) assessed each patient in the hospitals and nursing homes. For practical reasons, the measurements in home-care organisations were spread over $4 \mathrm{~d}$, and the health-care professional primarily responsible for the patient's care filled out the questionnaire during a home visit. To ensure that these measurements were consistent, another independent healthcare professional revisited a random sample of twenty patients per home-care organisation (Cohen's kappa of 0.87).

LPZ participants could find all the information needed for the measurements and data entry on a purpose-built website.

\section{Data analysis}

Statistical analyses were performed using SPSS version 13.0 (SPSS Inc., Chicago, IL) including descriptive frequency distributions for all variables. Differences between groups were 
tested using Student's $t$-tests, $\chi^{2}$ tests or ANOVA (with post hoc analysis using the Bonferroni method). Additionally, OR with $95 \%$ CI were calculated.

To confirm associations found in the univariate analysis, a multivariate binary logistic regression analysis was performed separately for hospitals, nursing homes and home-care organisations, where OR with $95 \% \mathrm{CI}$ were calculated once again. The independent variable was malnourished/well nourished. Prior to analysis, data were assessed for congruence with regression assumption. The independent variables were checked for possible interaction, confounding and multicollinearity. Variables that remained significant at the 0.01 level were presented. This level was seen as significant due to the large sample size. When a group was analysed separately, it had to consist of more than 100 patients for the findings to be of statistical value.

\section{Results}

As we were rigid in requiring complete nutritional datasets (BMI (weight and height), weight loss and data on intake), patients with partial datasets and those younger than 18 years ( $n$ 394) were excluded from the analysis. This resulted in the total exclusion of 12459 patients due to missing data on BMI $(n$ 7516) and weight loss $(n 4549)$ of the original 25342 participants. The remaining 12883 (8028 hospital patients, 2061 nursing home patients and 2794 home-care patients) were analysed in the present study.

Excluded patient characteristics (time since admission, sex, age, disease type and comorbidity), stratified by setting and the ward types, were not significantly different from those of the included patients.

Table 1 shows the included patients' characteristics separately for hospitals, nursing homes and home-care organisations.
Compared with those in hospitals, patients in nursing homes and home care were significantly older, and more often females. In hospitals, sex was more equally divided. In hospitals and home care, most patients had heart and coronary diseases and significantly higher BMI, while more patients in nursing homes had dementia.

\section{Malnutrition prevalence}

Table 2 shows malnutrition prevalence and malnourished patients' characteristics in hospitals, nursing homes and home-care organisations. It reveals significant differences in prevalence rates between the three. Hospitals had the highest malnutrition prevalence rate $(23.8 \%)$, followed by homecare organisations $(21.7 \%)$ and nursing homes (19.2\%). Fig. 1 presents malnutrition prevalence per ward type for hospitals and nursing homes. Home care was omitted as it has no identifiable wards.

Fig. 1 also shows that the highest malnutrition prevalence rates occur in psychogeriatric wards in nursing homes, and in geriatric wards in hospitals. In nursing homes, the prevalence rate varied from $13.3 \%$ in somatic wards to $22.8 \%$ in psychogeriatric wards (with $P<0.001$ difference), and in hospitals from $10.3 \%$ in coronary care wards to $32.9 \%$ in the geriatric wards (with $P<0.001$ difference).

\section{Characteristics of malnourished patients (univariate analysis)}

As shown in Table 2, a significant difference regarding sex was found only in nursing homes. Malnourished patients in hospitals and nursing homes were older than well-nourished patients, unlike in home care. Similarly, time since admission was significantly higher for malnourished than well-nourished patients in hospitals and nursing homes, while in home care this trend was the opposite.

Table 1. Patient characteristics

\begin{tabular}{|c|c|c|c|}
\hline & Hospital & Nursing home & Home care \\
\hline Organisations, $n(\%)$ & $57(49.5)$ & $39(34.0)$ & $19(16 \cdot 5)$ \\
\hline Patients, $n(\%)$ & $8028(62 \cdot 3)$ & $2061(16 \cdot 0)$ & $2794(21.7)$ \\
\hline \multicolumn{4}{|l|}{ Sex } \\
\hline Women, $n(\%)$ & $4199(52 \cdot 3)$ & $1407(68 \cdot 3)$ & $1754(62 \cdot 8)$ \\
\hline Men, $n(\%)$ & $3829(47.7)$ & $654\left(31 \cdot 7^{\star}\right)$ & $1040(37 \cdot 2 *)$ \\
\hline Age in years (SD) & $65.2\left(16 \cdot 0^{a b}\right)$ & $80 \cdot 3\left(10 \cdot 0^{c}\right)$ & $76 \cdot 2(12 \cdot 0)$ \\
\hline $\mathrm{BMI}(\mathrm{SD})$ & $25.8\left(4.9^{\mathrm{a}}\right)$ & $24.1\left(5 \cdot 1^{c}\right)$ & $25.9(5 \cdot 3)$ \\
\hline Undesired weight loss (\%) & $19 \cdot 6$ & $6 \cdot 8$ & 13.7 \\
\hline Time since admission in days (SD) & $34.7(5.9)$ & $829.9(435.1)$ & $879.2(310 \cdot 3)$ \\
\hline \multicolumn{4}{|l|}{ Diseases } \\
\hline Infection (\%) & $682\left(8.5^{\mathrm{ab}}\right)$ & $44(2 \cdot 1)$ & $60(2 \cdot 1)$ \\
\hline Cancer (\%) & $1087\left(13.5^{\mathrm{ab}}\right)$ & $88\left(4 \cdot 3^{\mathrm{c}}\right)$ & $366(13.1)$ \\
\hline Diabetes mellitus (\%) & $1009\left(12 \cdot 6^{\mathrm{b}}\right)$ & $285\left(13.8^{c}\right)$ & $585(20.9)$ \\
\hline Blood diseases (\%) & $303(3.8)$ & $48(2.3)$ & $66(2.4)$ \\
\hline Dementia (\%) & $301\left(3 \cdot 7^{\mathrm{ab}}\right)$ & $1262\left(61 \cdot 3^{\mathrm{C}}\right)$ & $339(12 \cdot 1)$ \\
\hline Heart and coronary diseases (\%) & $2606\left(32.5^{\mathrm{ab}}\right)$ & $425\left(20.6^{c}\right)$ & $743(26 \cdot 6)$ \\
\hline Stroke (CVA, \%) & $512\left(6.4^{\mathrm{a}}\right)$ & $512\left(24.9^{c}\right)$ & $338(8.5)$ \\
\hline COPD (\%) & $1554\left(19.4^{\mathrm{ab}}\right)$ & $147\left(7 \cdot 1^{c}\right)$ & $377(13.5)$ \\
\hline Diseases of the gastrointestinal tract (\%) & $1554\left(18.4^{\mathrm{ab}}\right)$ & $133(6.5)$ & $262(9.4)$ \\
\hline Musculoskeletal disorders (\%) & $1478(18.4)$ & $280\left(13.6^{c}\right)$ & $606(21 \cdot 7)$ \\
\hline Mean number of prevalent diseases (SD) & $1.64^{\mathrm{a}}(0.5)$ & $2.96^{\mathrm{b}}(0.8)$ & $2.13(0.7)$ \\
\hline
\end{tabular}

CVA, cerebrovascular accident; COPD, chronic obstructive pulmonary disease.

${ }^{a}$ Significant difference between hospitals and nursing homes.

bSignificant difference between hospitals and home care

${ }^{c}$ Significant difference between nursing homes and home care.

*Significant difference between men and women. 
Table 2. Prevalence rates of malnutrition and characteristics of malnourished and not malnourished patients

\begin{tabular}{|c|c|c|c|c|c|c|c|c|c|}
\hline & \multicolumn{3}{|c|}{ Hospital ( $n$ 8028) } & \multicolumn{3}{|c|}{ Nursing homes ( $n$ 2061) } & \multicolumn{3}{|c|}{ Home care $(n 2794)$} \\
\hline & $M+$ & $\mathrm{M}-$ & $P$ value & $\mathrm{M}+$ & $\mathrm{M}-$ & $P$ value & $\mathrm{M}+$ & $\mathrm{M}-$ & $P$ value \\
\hline \multirow[t]{2}{*}{ Prevalence (\%) } & $23 \cdot 8$ & $76 \cdot 2$ & & $19 \cdot 2$ & $80 \cdot 8$ & & $21 \cdot 7$ & $78 \cdot 3$ & \\
\hline & & $<0.001^{\mathrm{c} *}$ & & & $<0.001^{*}$ \\
\hline Women & $23.2 \%$ & & & $21.2 \%$ & & & $21.7 \%$ & & \\
\hline Men & $24.5 \%$ & & 0.088 & $15.0 \%$ & & $<0.001$ & $21.7 \%$ & & 0.507 \\
\hline Age in years $(\mathrm{SD})$ & $66 \cdot 2(16 \cdot 0)$ & $64.8(16.0)$ & $<0.060$ & $81.2(10.0)$ & $80.0(11.0)$ & $<0.070$ & $75.4(13.0)$ & $77.0(11.0)$ & $<0.060$ \\
\hline Time since admission in days (SD) & $38.3(6 \cdot 1)$ & $33.6(5.5)$ & 0.100 & $843.6(433.1)$ & $826 \cdot 6(436 \cdot 1)$ & $<0.001$ & $696.3(210 \cdot 3)$ & $930.5(290 \cdot 3)$ & $<0.001$ \\
\hline \multicolumn{10}{|l|}{ Disease } \\
\hline Infection & $33.1 \%$ & $66.9 \%$ & $<0.001$ & - & - & - & - & - & - \\
\hline Cancer & $40.7 \%$ & $59.3 \%$ & 0.004 & - & - & - & $51 \cdot 1 \%$ & $48.9 \%$ & 0.009 \\
\hline Diabetes mellitus & $21.9 \%$ & $78.1 \%$ & $<0.001$ & $10.9 \%$ & $89.1 \%$ & $<0.001$ & $15.4 \%$ & $84.6 \%$ & $<0.001$ \\
\hline Blood diseases & $37.6 \%$ & $62.4 \%$ & $<0.001$ & - & - & - & - & - & - \\
\hline Dementia & $29.2 \%$ & $70 \cdot 8 \%$ & $<0.001$ & $22.1 \%$ & $77.9 \%$ & $<0.001$ & $20.4 \%$ & $79.6 \%$ & $<0.001$ \\
\hline Heart and coronary & $20.9 \%$ & $79.1 \%$ & $<0.001$ & $17.9 \%$ & $82.1 \%$ & $<0.001$ & $20 \cdot 1 \%$ & $79.9 \%$ & $<0.001$ \\
\hline Stroke (CVA) & $19.7 \%$ & $80.3 \%$ & $<0.001$ & $15.4 \%$ & $84.6 \%$ & $<0.001$ & $12.6 \%$ & $87.4 \%$ & $<0.001$ \\
\hline COPD & $29.6 \%$ & $70.4 \%$ & $<0.001$ & $23.1 \%$ & $76.9 \%$ & $<0.001$ & $22.8 \%$ & $77 \cdot 2 \%$ & $<0.001$ \\
\hline Gastrointestinal tract & $37.3 \%$ & $62.7 \%$ & $<0.001$ & $20.3 \%$ & $79.6 \%$ & $<0.001$ & $32.4 \%$ & $67.6 \%$ & $<0.001$ \\
\hline Musculoskeletal disorders & $15 \cdot 3 \%$ & $84.7 \%$ & $<0.001$ & $20.4 \%$ & $79.6 \%$ & $<0.001$ & $18 \cdot 8 \%$ & $81.2 \%$ & $<0.001$ \\
\hline Mean number of prevalent diseases (SD) & $1.89(0.6)$ & $1.56(0.5)$ & 0.157 & $3.09(0.8)$ & $2.93(0.8)$ & 0.268 & $2.27(0.7)$ & $2.10(0.7)$ & 0.271 \\
\hline
\end{tabular}

$\mathrm{M}+$, malnourished; $\mathrm{M}-$, well nourished;,$-<100$ participants and no further analysis performed; CVA, cerebrovascular accident; COPD, chronic obstructive pulmonary disease. $P<0.01$ is significant. Significant difference between hospitals and nursing homes.

Significant difference between hospitals and home care.

*ANOVA between types of organisations. 


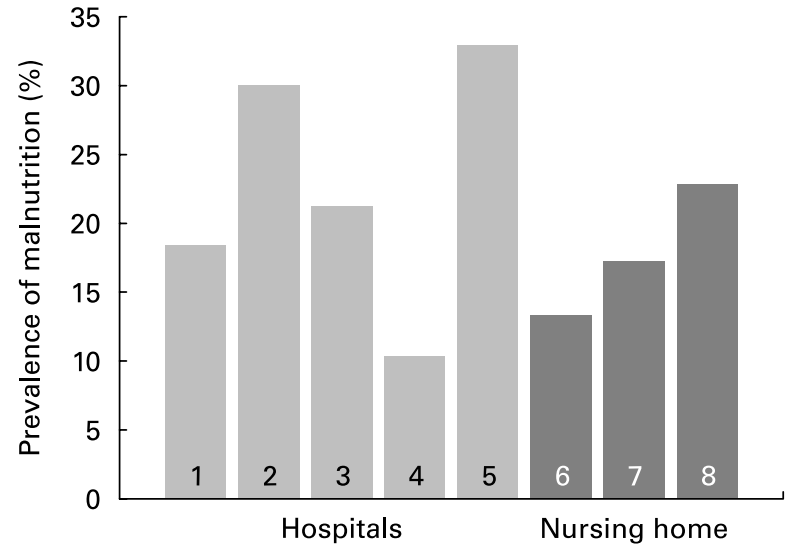

Fig. 1. Malnutrition prevalence in different hospital and nursing home wards: 1 , surgical wards $(\square)$; 2 , internal medicine wards $(\square)$; 3, intensive care unit wards $(\square)$; 4, coronary care wards $(\square)$; 5 , geriatric wards $(\square)$; 6, somatic wards ( $\square$ ); 7, somatic rehabilitation wards $(\square) ; 8$, psychogeriatric wards ( $\square$ ).

In hospitals, blood diseases, gastrointestinal tract diseases and cancer correlated more often with malnutrition. In nursing homes, dementia and chronic obstructive pulmonary disease were more often associated with malnutrition, while in home-care organisations patients with cancer and gastrointestinal tract diseases were more often malnourished.

Fig. 2 shows that malnutrition is associated with increasing age, especially in nursing homes. Fig. 3 shows increasing malnutrition prevalence in hospitals with increasing comorbidity.

\section{Factors associated with malnutrition (multivariate analysis)}

To confirm associations found in univariate analysis, a multivariate logistic regression analysis was performed for hospitals, nursing homes and home-care organisations separately. The factors sex, age, ward type, disease and time since admission were analysed as dependent variables, with malnourished/well nourished as the independent variable. Table 3 shows the analysis results per institution type (hospitals, nursing homes or home-care organisations). Only factors significantly related to malnutrition are shown.

In the multivariate analysis, no association with age, age group, ward type or time since admission was found in hospitals, nursing homes or home-care organisations. An association with being female was found only in nursing homes. In hospitals, particularly blood diseases, gastrointestinal tract diseases,

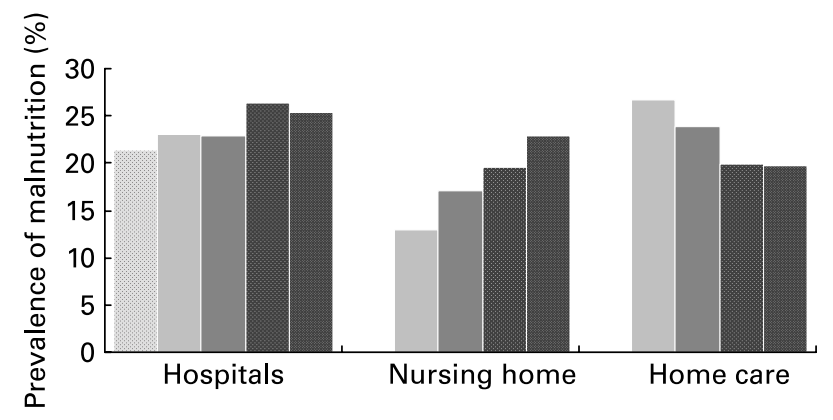

Fig. 2. Malnutrition prevalence in different age groups: age 31-45 years $(\square)$ age 45-60 years ( $\square$ ); age $61-75$ ( $\square$ ); age 76-90 years ( $\square$ ); age above 90 years ( $\square$ ); Chi-square for trend: $P<0.01$ for nursing homes, $P=0.02$ for home care and $P=0.06$ for hospitals.

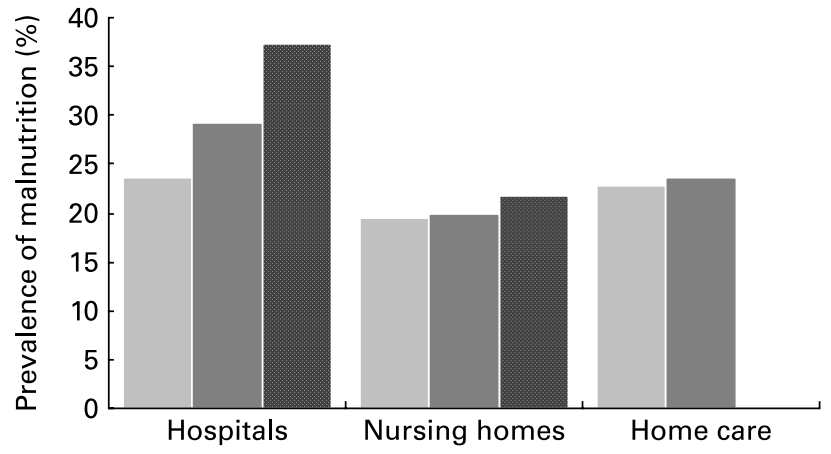

Fig. 3. Malnutrition prevalence with increasing comorbidity: one to two diseases $(\square)$; three to four diseases $(\square)$; five to six diseases $(\square) \cdot \chi^{2}$ for trend: $P=0.01$ for hospitals, $P=0.06$ for nursing homes and $P=0.08$ for home care. Home care: group five to six diseases to small $n<100$.

cancer, dementia, infection and chronic obstructive pulmonary disease were associated with malnutrition. In nursing homes, patients with dementia were more often malnourished, while in home care, cancer, gastrointestinal tract diseases and diabetes mellitus were again most often associated with malnutrition. Patients in home care with diabetes mellitus had a significantly reduced chance of malnutrition. Interactions were tested but found not significant.

\section{Discussion}

LPZ is one of the first large-scale, multi-centre prevalence studies focusing on health-care problems carried out annually in The Netherlands. The purpose of this study was to investigate the prevalence of malnutrition, and to assess the association between relevant influencing factors in Dutch hospitals, nursing homes and home-care organisations and the prevalence of malnutrition.

\section{Malnutrition prevalence}

Our study showed a malnutrition prevalence rate ranging from $19.2 \%$ in nursing homes to $23.8 \%$ in hospitals. Comparing these rates to other studies in the field is a real challenge as they are largely dependent on the operationalisation of malnutrition (most studies use different screening tools and elements) as well as the population and setting investigated. Yet, a general comparison of our results with these studies shows that our prevalence rates are within the higher range of Stratton et al.'s ${ }^{(6)}$ reviews, and higher than that indicated by the first Dutch national survey conducted by dietitians in $2001^{(2)}$. Still, comparing this LPZ prevalence study with the earlier national survey is difficult, as in 2001 malnutrition was operationalised only by weight loss. In this study, we included a much larger sample of patients and focused on BMI, weight loss and intake. A recent German study by Pirlich et al. ${ }^{(20)}$, however, showed hospital results comparable to ours, while a large study by Waitzberg et al. ${ }^{(17)}$ of 4000 hospital patients in Brazil showed a much larger percentage $(48.1 \%)$ of malnourished patients.

Geriatric wards in hospitals and psychogeriatric wards in nursing homes exhibited the highest malnutrition prevalence rates, a finding that is again comparable to other studies $^{(2,14,18)}$. These other studies, however, explained their 
Table 3. Factors related to malnutrition, assessed by multivariate logistic regression analysis per type of health-care organisation*

\begin{tabular}{lrrr}
\hline Variables in the model & $P$ value & OR & $95 \% \mathrm{Cl}$ \\
\hline Hospitals & & & \\
$\quad$ Infection & $<0.001$ & 1.70 & $1.43,2.03$ \\
Cancer & $<0.001$ & 2.74 & $2.39,3.15$ \\
$\quad$ Dementia & $<0.001$ & 1.53 & $1.17,2.85$ \\
Blood diseases & $<0.001$ & 2.22 & $1.73,2.85$ \\
COPD & $<0.001$ & 1.58 & $1.40,1.80$ \\
$\quad$ Diseases of the gastrointestinal tract & $<0.001$ & 2.46 & $2 \cdot 16,2.78$ \\
Nursing home & & & \\
$\quad$ Sex: female & 0.004 & 1.45 & $1.13,1.87$ \\
$\quad$ Dementia & $<0.001$ & 1.55 & $1.21,1.97$ \\
Home care & $<0.001$ & 4.19 & $3.32,5.29$ \\
$\quad$ Cancer & $<0.001$ & 0.67 & $0.52,0.87$ \\
$\quad$ Diabetes mellitus & 0.003 & 1.58 & $1.18,2.11$ \\
$\quad$ Diseases of the gastrointestinal tract & & &
\end{tabular}

COPD, chronic obstructive pulmonary disease.

${ }^{*}$ Only variables that remain significant $(P<0.01)$ are presented.

high prevalence rates by the higher age and vulnerability of the patient groups; in this study, no influence of or interaction with age was found in the logistic regression analysis or additional analysis for the different wards.

\section{Factors associated with the prevalence of malnutrition}

As mentioned, the literature shows that higher age is a risk factor for developing malnutrition ${ }^{(4,17-20)}$. In this study, an age effect was found in the univariate analysis within the nursing homes and home care (Fig. 1), but this effect disappeared in the multivariate analysis (Table 3). The age effect revealed in other studies as well as in our univariate analysis may be due to the fact that higher age is associated with an overall increase in disease prevalence ${ }^{(4,17)}$.

Fig. 2 shows a trend of increasing age with increasing malnutrition prevalence in the univariate analysis of nursing homes. In home care, this trend was opposite; with increasing age, malnutrition prevalence decreased. This contradiction could be explained by the fact that sicker older persons are probably more often admitted to nursing homes, thus leaving a healthier population in the home-care setting. This would also fit with the time since admission (receiving care) for home care in Table 2; in home care, well-nourished patients had a longer mean 'time since admission' than malnourished patients.

Perissinotto et al. ${ }^{(19)}$ found that body composition changes occurred differently in men and women in the various phases of ageing, and thus influenced the assessment and screening of malnutrition. Their study indicated that in nursing homes women had a higher chance of becoming malnourished than men. However, like Pirlich et al. ${ }^{(18)}$, we found no relationship between sex and malnutrition in hospitals.

Disease and malnutrition are related. Table 2 shows that malnourished patients have a higher mean number of diseases per patient than those who are well nourished. Furthermore, patients with cancer showed a very high risk of being malnourished both in hospitals and home-care organisations, a result also identified in other studies ${ }^{(2,6,18-29)}$.

In nursing homes, patients with dementia had a higher risk of malnutrition; this finding is consistent with other studies in nursing homes ${ }^{(28,29)}$. However, patients with diabetes mellitus in home care had a significantly reduced chance of malnutrition, a finding not supported by other studies. A possible reason for this could be that diabetes mellitus patients are expected to be overweight rather than underweight.

\section{Limitations of this national screening}

Although our study sample was large (n 25342), many patients were excluded if their nutritional data were incomplete; we felt it very important to have complete and reliable data. Datasets, in particular, for elderly patients were often incomplete as caregivers found it difficult to actually weigh patients and measure their height. Likewise, Stratton et al. ${ }^{(30)}$ indicated that measuring height and weight, particularly in elderly patients, is difficult; in their study, only $56 \%$ of the elderly patients could be weighed.

Nevertheless, the group included in our analysis is a representative sample, with no significant differences in patient characteristics (time since admission, age, sex and number and type of disease) and type of ward compared with the excluded group, which makes the results robust and the sample quite unique.

A particular difficulty with cross-sectional studies focusing on correlations is the fact that the progression over time of certain disorders and their possible risk factors cannot be measured by one-time measurement. As the dependent and independent variables are selected at one and the same time, causality cannot be drawn. For example, disease and malnutrition interact such that the disease may cause secondary malnutrition, or malnutrition may adversely influence underlying disease.

The large LPZ population is heterogeneous and incorporates patients from different age groups (range: 18-104 years) and health-care settings, making the operationalisation of malnutrition extremely difficult as there is no consensus on a valid and reliable instrument for quick and easy measurement that suits the whole group at once. However, based on the literature and consultation with experts in the malnutrition field in The Netherlands, we did achieve consensus on our definition. We realise, though, that the BMI cut-off points and further operationalisation used are debatable, may not be totally appropriate for all age groups, and could possibly result in an underestimation of malnutrition prevalence.

In our operationalisation, undesired weight loss in kilograms was used instead of percentage of weight loss. We do believe it would have been preferable to use absolute percentages; yet, fixed cut-off points were easier for the nurses who filled out the questionnaires than having to calculate percentage of weight loss. Still, we had to deal with a large number of missing values in the dataset.

As LPZ was measured on a large scale and to make it easier for the nurses to fill out the questionnaire, questions on diseases were clustered per disease group. Thus, our data do not specify the disease type each patient had at the time of measurement. We realise that this limits further analysis on the disease variable.

An annual, large-scale, multi-centre study like LPZ focusing on health-care problems such as malnutrition is unique in Europe. This study shows that malnutrition is still a substantial 
problem in hospitals, nursing homes and home care in The Netherlands. Despite growing attention to the problem, more continued alertness is required. Therefore, in The Netherlands the LPZ's prevalence measurement of malnutrition will be repeated annually to achieve structural and ongoing awareness of the problem within health-care organisations, as well as to raise national awareness of its approach.

\section{Acknowledgements}

We thank Nutricia Netherlands for providing an unrestricted grant to perform this study. There are no conflicts of interest to report. J. M., J. S., M. B., T. D., M. J. and R. H. contributed to the design of the study. J. M., M. J. and R. H. helped in data collection. Data analysis was done by J. M. and R. H. The manuscript was written by J. M. J. M., J. S., M. B., T. D. and R. H. provided significant advice or consultation. Final manuscript approval was done by J. M., J. S., M. B., T. D., M. J. and R. H.

\section{References}

1. Chen CC, Schilling LS \& Lyder CH (2001) A concept analysis of malnutrition in the elderly. J Adv Nurs 36, 131-142.

2. Kruizenga HM, Wierdsma NJ, van Bokhorst-de van der Schueren MA, Hollander HJ, Jonkers-Schuitema CF, Van der Heijden E, Melis GC \& Van Staveren WA (2003) Screening of nutritional status in The Netherlands. Clin Nutr 22, 147-152.

3. Lochs H \& Dervenis C (2003) Malnutrition - the ignored risk factor. Dig Dis 21, 196-197.

4. Volkert D, Kruse W, Oster P \& Schlierf G (1992) Malnutrition in geriatric patients: diagnoses and prognostic significance of nutritional parameters. Ann Nutr Metab 36, 97-112.

5. Charles R, Mulligan S \& O'Neill D (1999) The identification and assessment of undernutrition in patients admitted to the age-related health care unit of an acute Dublin General Hospital. Ir J Med Sci 168, 180-185.

6. Stratton RJ, Green CJ \& Elia M (2003) Disease-Related Malnutrition: An Evidence-Based Approach to Treatment. Cambridge: CABI Publishing.

7. Detsky AS, Baker JP, O'Rourke K, Johnston N, Whitwell J, Mendelson RA \& Jeejeebhoy KN (1987) Predicting nutritionassociated complications for patients undergoing gastrointestinal surgery. J Parenter Enteral Nutr 11, 440-446.

8. Bökkerink S \& Coenen C (2002) Assessment of the SROZ through dietetics in research. Identifying the validity and reliability of the undernutrition risk screening instrument (SROZ) in hospital patients. Universitair Medisch Centrum ST Radboud.

9. Elia M (2000). Guidelines for Detection and Management of Malnutrition. Maidenhead: Malnutrition Advisory Group (MAG), Standing Committee of BAPEN.

10. Correia MI \& Waitzberg DL (2003) The impact of malnutrition on morbidity, mortality, length of hospital stay and costs evaluated through a multivariate model analysis. Clin Nutr 22, 235-239.

11. Sullivan DH \& Walls RC (1995) The risk of life-threatening complications in a select population of geriatric patients, the impact of nutritional status. J Am Coll Nutr 14, 29-36.

12. Tucker HN \& Miguel SG (1996) Cost containment through nutritional intervention. Nutr Rev 54, 111-121.
13. Vellas BJ, Hunt WC, Romero LJ, Koehler KM, Baumgartner RN \& Garry PJ (1997) Changes in nutritional status and patterns of morbidity among free-living elderly persons: a 10-year longitudinal study. Nutrition 13, 515-519.

14. Martyn CN, Winter PD, Coles SJ \& Edington J (1998) Effect of nutritional status on use of health care resources by patients with chronic disease living in the community. Clin Nutr 17, 119-123.

15. National Audit Office (2000) Inpatient Admissions and Bed Management in NHS Acute Hospitals. London: The Stationery Office.

16. Correia MI \& Campos AC (2003) The prevalence of hospital malnutrition in Latin America: the multicenter ELAN study. Nutrition 19, 823-825.

17. Waitzberg DL, Caiaffa WT \& Correia MI (2001) Hospital malnutrition: the Brazilian National Survey (IBRANUTRI): a study of 4000 patients. Nutrition 17, 573-580.

18. Pirlich M, Schutz T, Norman K, et al. (2006) The German hospital malnutrition study. Clin Nutr 25, 563-572.

19. Perissinotto E, Pisent C, Sergi G, Grigoletto F \& Enzi G (2002) Anthropometric measurements in the elderly, age and gender differences. Br J Nutr 87, 177-186.

20. Pirlich M, Schutz T, Kemps M, Luhman N, Minko N, Lubke HJ, Rossnagel K, Willich S \& Lochs H (2005) Social risk factors for hospital malnutrition. Nutrition 21, 295-300.

21. World Health Organization (2000) Obesity: Preventing and Managing the Global Epidemic. Report of a WHO Consultation on Obesity No. 894. Geneva: WHO.

22. ASPEN Board of Clinical Directors (1987) Guidelines for the use of enteral nutrition in adult patient. $J$ Parenter Enteral Nutr 11, 435-439.

23. British Dietetic Association (1999) Nutritional Screening Tools. Professional Development Committee Briefing Paper No. 9. Birmingham: British Dietetic Association.

24. Elia M \& Lunn PG (1997) Biological markers of protein-energy malnutrition. Clin Nutr 16, 11-17.

25. van Bokhorst-de van der Schueren MA, Van Leeuwen PA, Sauerwein HP, Kuik DJ, Snow GB \& Quak JJ (1997) Assessment of malnutrition parameters in head and neck cancer and their relation to postoperative complications. Head Neck 19, 419-425.

26. Laviano A, Renvyle $T$ \& Yang Z (1996) From laboratory to bedside: new strategies in the treatment of malnutrition in cancer patients. Nutrition 12, 112-122.

27. Lipman TO (1991) Clinical trials of nutritional support in cancer. Parenteral and enteral therapy. Hematol Oncol Clin North Am 5, 91-102.

28. Vetta F, Ronzoni S, Taglieri G \& Bollea MR (1999) The impact of malnutrition on the quality of life in the elderly. Clin Nutr 18, 259-267.

29. Suominen M, Muurinen S, Routasalo P, Soini H, Suur-Uski I, Peiponen A, Finne-Soveri H \& Pitkala KH (2005) Malnutrition and associated factors among aged residents in all nursing homes in Helsinki. Eur J Clin Nutr 59, $578-583$.

30. Stratton RJ, King CL, Stroud MA, Jackson AA \& Elia M (2006) 'Malnutrition Universal Screening Tool' predicts mortality and length of hospital stay in acutely ill elderly. Br J Nutr 95, $325-330$. 